\title{
Aquaculture
}

\section{Measurement of reactive oxygen intermediate production in haemocytes of the penaeid shrimp, Penaeus vannamei}

\author{
Marcelo Muñoz ${ }^{\mathrm{a}}$, Ricardo Cedeño ${ }^{\mathrm{b}}$, Jenny Rodríguez ${ }^{\mathrm{b}}$, \\ Wil P.W. van der Knaap ${ }^{c}$, Eric Mialhe ${ }^{\mathrm{d}}$, Evelyne Bachère ${ }^{\mathrm{a}, *}$ \\ a IFREMER / CNRS / Université Montpellier 2, UMR 219 “ Défense et Résistance chez les Invertébrés \\ Marins”, CC 80, Place Eugène Bataillon, 34095 Montpellier, France \\ ${ }^{\mathrm{b}}$ Centro Nacional de Acuicultura e Investigaciones Marinas, Escuela Superior Politecnica del Litoral, \\ Guayaquil, Ecuador \\ ${ }^{\mathrm{c}}$ Fish Culture and Fisheries Group, Department of Animal Sciences, Wageningen Agricultural University, \\ P.O. Box 338, NL-6700 AH Wageningen, Netherlands \\ ${ }^{\mathrm{d}}$ French-Ecuadorian Cooperation, Embajada de Francia, Quito, Ecuador
}

Received 1 March 2000; accepted 9 May 2000

\begin{abstract}
A spectrophotometric nitroblue tetrazolium (NBT) reduction assay was used to demonstrate the production of superoxide anions $\left(\mathrm{O}_{2}^{-}\right)$by haemocytes of the white shrimp Penaeus vannamei. It was found that haemocytes, without receiving an experimental stimulant, showed a rather high background activity. Therefore, optimal parameters (number of haemocytes, type of incubation medium, type and concentration of stimulants) were first established, in order to obtain a reliable and reproducible quantitative assay. With this optimized assay, and using specific inhibitors, it was shown that it is indeed the production of $\mathrm{O}_{2}^{-}$that was measured. Activities varied strongly among individual shrimp specimens. Live bacteria, among these Vibrio strains, induced $\mathrm{O}_{2}^{-}$ production in the haemocytes, in a dose-dependent manner. Whereas Vibrio anguillarum and a probiotic strain of $V$. alginolyticus evoked clear reactions, a pathogenic strain of $V$. harveyi failed to elicit $\mathrm{O}_{2}^{-}$production in the haemocytes. It is discussed that this may explain this strain's capability of evading the host's oxidative microbicidal activity, which would be a virulence factor in these bacteria. Heat-killed bacteria hardly induced NBT reduction in the cells. The fungicide propiconazole or Tilt ${ }^{\circledR}$, found as a pollutant in the aquatic environment where the shrimp are reared, was tested for its effect on NBT reduction by the haemocytes. In haemocytes that did not
\end{abstract}

\footnotetext{
* Corresponding author. Tel.: +33-4-67-144710; fax: +33-4-67-144622.

E-mail address: evelyne.bachere@ifremer.fr (E. Bachère).
} 
receive an experimental stimulant, Tilt ${ }^{\circledR}$ induced the reduction of NBT in a dose-dependent manner. In experimentally stimulated haemocytes, however, Tilt ${ }^{\circledR}$ strongly reduced the reaction upon the stimulant PMA. Probable explanations for these seemingly controversial effects of Tilt ${ }^{\circledR}$ are discussed, as are possible consequences of this sort of pollutants for shrimp aquaculture. This easy to perform and relatively cheap and simple quantitative assay for measuring the activity of an oxidative microbicidal mechanism in shrimp haemocytes, appears quite reliable and may therefore prove to be a valuable tool for monitoring shrimp health and immunologic status. (C) 2000 Elsevier Science B.V. All rights reserved.

Keywords: Crustacea; Shrimp; Penaeus vannamei; Superoxide anion; NBT assay; Immune check-up

\section{Introduction}

Research in penaeid shrimp immunology has only recently become a priority because of the dramatically increasing impact of - mainly infectious - diseases on sustainability and economic durability of shrimp aquaculture. Crustacean immune responses are based on both cellular and humoral components, which cooperate to eliminate potentially infectious microorganisms. The first immune process is the recognition of microorganisms, and it is mediated by plasma proteins and by the haemocytes (Söderhäll and Cerenius, 1998). Phagocytosis, which represents an important way to eliminate microorganisms or foreign particles, has been well described and documented in invertebrates (Bayne, 1990). Whereas much attention has been devoted to recognition and opsonization processes, comparatively little is known about post-phagocytic events and the role of intracellular killing mechanisms against pathogens.

In mammalian phagocytic cells, the oxygen-dependent defence mechanism consists in the generation of reactive oxygen intermediates (ROIs) with powerful microbicidal activity (Babior, 1984). The phenomenon known as respiratory burst can be elicited, upon suitable stimulation, by soluble components such as phorbol myristate acetate (PMA), lectins, lipopolysaccharides (LPS) or by particulate phagocytic stimuli such as zymosan (yeast cell wall). The stimulation leads to increased consumption of oxygen of which the reduction, catalyzed by a membrane-bound enzyme, NAD(P)H-oxidase, gives rise to superoxide $\left(\mathrm{O}_{2}^{-}\right)$. Starting from superoxide, a number of reactions lead to the production of hydrogen peroxide $\left(\mathrm{H}_{2} \mathrm{O}_{2}\right)$, singlet oxygen $\left({ }^{1} \mathrm{O}_{2}\right)$, hydroxyl radical $(\mathrm{OH})$ and numerous other reactive products.

In invertebrates, this microbicidal system has been first demonstrated in gastropods (Dikkeboom et al., 1987; Adema et al., 1991). Then, it was shown in several marine bivalves (Larson et al., 1989; Bachère et al., 1991a), with a special attention to the interaction of the oxidative metabolism with specific intracellular parasites. Adaptations for avoiding or bypassing the haemocytic oxidative microbicidal system have been demonstrated in several pathogens, using in vitro host-pathogen models with isolated specific pathogens (Hervio et al., 1989; Le Gall et al., 1991; Volety and Chu, 1995).

In crustaceans, the demonstration of respiratory burst is quite recent. Using the method of ferricytochrome- $C$ reduction, Bell and Smith (1993) demonstrated the generation of superoxide anions by haemocytes of the decapod Carcinus maenas; working with separated haemocyte fractions, they showed that hyaline cells are responsi- 
ble for this activity, whereas the semi-granular and granular haemocytes would not be involved in the production of ROIs. In the penaeid shrimp, Penaeus monodon, Song and Hsieh (1994) have used two different methods for the demonstration of oxygen metabolism, leading to different results. The authors were able to spectrophotometrically detect the generation of oxygen metabolites, based on nitroblue tetrazolium (NBT) reduction. However, using a chemiluminescence (CL) method, the same elicitors used failed to elicit haemocyte activation. In contrast, CL activity has been successfully demonstrated in P. japonicus haemocytes upon PMA or zymosan stimulation (Bachère et al., 1995). These different results probably underline the need of method standardization in research of crustacean haemocyte functioning in vitro.

The present study was undertaken in order to explore a method for its possible applicability in marine aquaculture, more in particular shrimp farming. The respiratory burst was chosen as a parameter encompassing several immunological activities, viz. recognition, phagocytosis and cytotoxicity. To this end, the production of ROIs in the haemocytes of the white shrimp, P. vannamei was investigated using a quantitative microplate assay of the reduction of NBT. The functional capability of the haemocytes to generate a respiratory burst upon stimulation with standard stimuli was assessed. In addition, the interaction of the oxidative intracellular killing mechanism with bacteria has been studied. Some of these bacteria belong to the Vibrionaceae. We used a strain of Vibrio harveyi, associated with shrimp larvae mortalities linked to the "Bolitas" syndrome in Ecuador (Robertson et al., 1998) and a V. alginolyticus strain, designated Ili (I. Morales, personal communication). For this strain, a probiotic effect for $P$. vannamei has been shown in the laboratory.

Shrimp aquaculture in Ecuador has been developed mainly in the Gulf of Guayaquil. This aquatic environment has received an important number of xenobiotics from human activities. Among these pollutants there is a variety of biochemical compounds for control of pests of agronomic plants. The literature indicates that environmental contaminants can lead to non-infectious diseases. Indeed there is evidence for oxidative stress-related pathologies from pollutants in marine organisms (Ahmad, 1995). We chose the fungicide propiconazole or Tilt ${ }^{\circledR}$, used in banana production to control the black sigatoka disease, to study the effect of an environmental stressor on the respiratory burst.

\section{Materials and methods}

\subsection{Reagents}

Laminarin (L 9634; Sigma), extracted from Laminaria digitata, was prepared at 60 $\mathrm{mg} / \mathrm{ml}$ in modified Hank's balanced salt solution (Gibco) containing $2.6 \mathrm{~g} / 1 \mathrm{HEPES}$, $85 \mathrm{mM} \mathrm{NaCl}, \mathrm{pH}$ 7.2, 780 mosM (MHBSS).

LPS from Escherichia coli serotype 055:B5 (Sigma) were dissolved at $100 \mu \mathrm{g} / \mathrm{ml}$ in MHBSS.

A suspension of yeast cell walls (Zymosan A; Sigma; $40 \mathrm{mg} / \mathrm{ml}$ ) in filter-sterilized seawater $(\mathrm{SSW})$ was heated at $100^{\circ} \mathrm{C}$ for $30 \mathrm{~min}$, washed twice and resuspended in SSW at a density of $1.43 \times 10^{8}$ particles $/ \mathrm{ml}$. 
PMA (Sigma) was prepared in DMSO (dimethyl sulfoxide; Sigma) at a concentration of $10 \mathrm{mg} / \mathrm{ml}$.

All suspensions and solutions were stored at $-20^{\circ} \mathrm{C}$ and thawed just before use.

Superoxide dismutase (SOD; Sigma) stock solution was prepared to $13500 \mathrm{U} / \mathrm{ml}$ in distilled water. $N$-ethylmaleimide (NEM; Sigma), used as an inhibitor of cytosolic cofactors leading to a deactivation of NADPH oxidase (Akard et al., 1988), was prepared as a 0.1-M stock solution in MHBSS. Iodoacetamide (Sigma), an inhibitor of the respiratory burst which is thought to block glycolysis (Pick et al., 1981) was prepared at $30 \mathrm{mM}$ in MHBSS.

NBT (N 6876, Sigma) stock solution was prepared at $10 \mathrm{mg} / \mathrm{ml}$ in distilled water and kept at $4{ }^{\circ} \mathrm{C}$ in the dark. From this stock solution, a NBT working solution was prepared in culture medium at $0.3 \%$ just before utilization. This solution was diluted three times in each well, giving a final concentration of NBT in the well of $0.1 \%$.

Propiconazole (Tilt ${ }^{\circledR}$, Ciba) was diluted in MHBSS with $12 \mathrm{mM} \mathrm{Ca}^{2+}$ and $26 \mathrm{mM}$ $\mathrm{Mg}^{2+}$ at 3, 30 and $300 \mathrm{ppb}$.

\subsection{Bacteria}

$V$. harveyi, a pathogenic strain involved in the "Bolitas" syndrome in Ecuador, had been isolated in CENAIM (Ecuador). E. coli D31, a streptomycin-resistant mutant, was obtained from Dr. J. Hoffmann (IBMC, Strasbourg, France); Micrococcus luteus A270 was from the Pasteur Institute Collection (Paris, France); V. alginolyticus had been isolated in Ecuadorian hatcheries; this strain has a probiotic effect in shrimp larvae (I. Morales, personal communication). V. anguillarum V408 was obtained from the IFREMER laboratory of Palavas (France). E. coli D31 and M. luteus were grown at $37^{\circ} \mathrm{C}$ in LB medium containing 1\% Bacto-tryptone (Difco), 0.5\% Bacto-yeast (Difco) and 1\% $\mathrm{NaCl}$. The marine bacterial strains were grown in Marine Broth (Difco) at $25^{\circ} \mathrm{C}$.

\subsection{Shrimp and haemolymph collection}

P. vannamei shrimps, originating from a local shrimp farm (OPUMAR) in Provincia del Guayas, Ecuador, were maintained in the laboratory in 500-1 tanks with a constant flow of circulating seawater. Animals, at about $13 \mathrm{~g}$, in intermoult stage were used in the experiments.

Haemolymph (about $300 \mu \mathrm{l}$ per shrimp) was obtained from the ventral sinus located at the base of the first abdominal segment. The samples were collected using a 23-gauge needle and $1 \mathrm{ml}$ syringe containing $300-\mu \mathrm{l}$ pre-cooled $\left(4^{\circ} \mathrm{C}\right) 10 \%$ sodium citrate solution in distilled water, used as anticoagulant. Haemolymph samples from 20 animals were pooled or kept individually, and the haemocytes were counted with a haemocytometer (Erma).

\subsection{Superoxide assay: NBT reduction}

General protocol: The reduction of NBT to insoluble blue formazan was used as a probe for superoxide generation, although it is not entirely specific for $\mathrm{O}_{2}^{-}$(Auclair and Voisin, 1985). 
A determined number of haemocytes (usually $5 \times 10^{5}$ ) were deposited in triplicate, in $100 \mu \mathrm{l}$ final volume of medium (see below) in wells of a 96-well microtiterplate (Corning, Sigma M-0156) and incubated in humid conditions, during $30 \mathrm{~min}$ at room temperature for adherence of the haemocytes. The supernatants were then eliminated and replaced by $50 \mu \mathrm{l}$ of medium, after which were added $50 \mu \mathrm{l}$ of medium containing respiratory burst elicitors or not, and with or without inhibitors. Then, $50 \mu 1$ of $0.3 \%$ NBT working solution in the appropriate medium were immediately distributed to the wells. Following a 2-h incubation, the supernatants were removed and the haemocytes were fixed by the addition of 200- $\mu$ l absolute methanol, washed twice with $70 \%$ methanol, then dried. The formazan deposits were solubilized in $120 \mu \mathrm{l}, 2 \mathrm{M} \mathrm{KOH}$ and $140 \mu 1$ DMSO. After homogenization of the contents in the wells, the extinction was read at $620 \mathrm{~nm}$ in a Labsystem Multiskan spectrophotometer.

\subsection{Medium screening}

Shrimp haemocytes $\left(5 \times 10^{5}\right)$ were incubated in $50 \mu$ l of a mixture of haemolymph-anticoagulant and $50 \mu \mathrm{l}$ of culture medium (using different culture media, see below). In the first assays it was tested, if the presence of the haemolymph plasma and of citrate during the NBT reaction has some effect on superoxide production. For this, $50 \mu \mathrm{l}$ of the mixture hemolymph-anticoagulant culture medium was left in the well, and $50 \mu \mathrm{l}$ of medium with or without $10 \mu \mathrm{g} / \mathrm{ml}$ PMA as the stimulus, and $50 \mu \mathrm{l}$ of NBT in the medium were added.

At the same time, and with the same pool of haemocytes $\left(5 \times 10^{5}\right.$ per well), NBT reduction was performed in the same set of media in the absence of plasma and citrate, using the general protocol.

The media that were tested were: Dulbecco's phosphate-buffered saline (PBS, Sigma) $1 \times$ and $2 \times$, SSW, MHBSS without $\mathrm{Ca}^{2+}$ and $\mathrm{Mg}^{2+}$, and MHBSS supplemented with different final concentrations of $\mathrm{Ca}^{2+}$ and $\mathrm{Mg}^{2+}$, viz. MHBSS-1: $3 \mathrm{mM} \mathrm{Ca}^{2+}$ and 6.5 $\mathrm{mM} \mathrm{Mg}^{2+}$, MHBSS-2: $6 \mathrm{mM} \mathrm{Ca}^{2+}$ and $13 \mathrm{mM} \mathrm{Mg}^{2+}$ and MHBSS-3: $9 \mathrm{mM} \mathrm{Ca}^{2+}$ and $19.5 \mathrm{mM} \mathrm{Mg}^{2+}$.

\subsection{Elicitors}

Various stimulants were assayed: laminarin at final concentrations of 1,5 and 10 $\mathrm{mg} / \mathrm{ml}$, LPS used at 4, 20 and $40 \mu \mathrm{g} / \mathrm{ml}$, zymosan at the ratio particles to haemocyte of $5 / 1,10 / 1,20 / 1$, PMA at final concentrations of 1,5 and $10 \mu \mathrm{g} / \mathrm{ml}$. The incubation medium was MHBSS-2.

\subsection{Haemocyte concentration}

Shrimp haemocytes $\left(1 \times 10^{6}, 5 \times 10^{5}\right.$ and $\left.1 \times 10^{5}\right)$ were distributed in microplate wells as previously described. They were stimulated with the different elicitors, PMA $(10 \mu \mathrm{g} / \mathrm{ml})$, laminarin $(10 \mathrm{mg} / \mathrm{ml})$ and zymosan $(10 / 1)$ in MHBSS-2. 


\subsection{Inhibition assays}

SOD was used at 75, 150 and $300 \mathrm{U} / \mu \mathrm{l}, \mathrm{NEM}$ at 1,3 and $5 \mathrm{mM}$ and iodoacetamide at 1,10 and $20 \mathrm{mM}$. The inhibitors were administered in $50 \mu \mathrm{l}$ MHBSS with $12 \mathrm{mM}$ $\mathrm{Ca}^{2+}$ and $26 \mathrm{mM} \mathrm{Mg}{ }^{2+}$ containing $10 \mu \mathrm{g} / \mathrm{ml} \mathrm{PMA}$ as the stimulant.

\subsection{NBT reduction assay with bacteria}

NBT reduction assays were performed, as previously described, using as phagocytic stimulant the different bacteria $V$. harveyi, E. coli D31, M. luteus, V. alginolyticus and $V$. anguillarum. The logarithmic-phase bacterial cultures were pelleted $(5000 \mathrm{rpm}, 15$ min) and after resuspension in MHBSS with $12 \mathrm{mM} \mathrm{Ca}^{2+}$ and $26 \mathrm{mM} \mathrm{Mg}^{2+}, 50 \mu \mathrm{l}$ of bacterial suspensions were added to the haemocytes, in triplicate. Both live and heat-killed bacteria were used.

\subsection{NBT reduction assay in presence of propiconazole}

NBT reduction assays were performed in presence of the fungicide propiconazole (Tilt ${ }^{\circledR}$ ) at final concentrations of 1,10 and $100 \mathrm{ppb}$ in the wells. In order to increase the sensibility of the test, $1 \times 10^{6}$ cells were deposited per well. The control was a similar reaction without the antifungal agent.

The volume of haemolymph necessary to obtain $1 \times 10^{6}$ cells was incubated in presence of the same volume of MHBSS-2, for $30 \mathrm{~min}$ at room temperature. The supernatants were eliminated and replaced by $50 \mu \mathrm{l}$ of MHBSS-2; immediately added were $50 \mu \mathrm{l}$ of MHBSS $12 \mathrm{mM} \mathrm{Ca}^{2+}$ and $26 \mathrm{mM} \mathrm{Mg}^{2+}$ (with or without Tilt ${ }^{\circledR}$ ) in presence or absence of $10 \mu \mathrm{g} / \mathrm{ml}$ PMA, and $50 \mu \mathrm{l}$ of NBT working solution. After $2 \mathrm{~h}$ of incubation, the fixation and solubilization were performed following the general protocol.

\subsection{Statistical analyses}

All the measurements were made in triplicate. The results were analyzed using the Duncan new multiple range test $(p=0.05)$ at $95 \%$ confidence level with the Super Anova $(\mathrm{S}-\mathrm{E}+)$ program.

\section{Results}

In order to assess the different parameters leading to an optimal superoxide assay in terms of reliability and sensitivity, not only the level of stimulated activity was considered (optical density (OD) of solubilized formazan deposits). Unstimulated haemocytes, in the absence of an inhibitor, always showed a considerable base activity. 
Therefore, the haemocyte activity was expressed as the ratio of OD620 from the stimulated haemocytes to the OD 620 of control haemocytes.

Observation with an inverted microscope showed that the haemocytes had phagocytosed zymosan particles.

\subsection{Optimization of superoxide assay}

\subsubsection{Culture medium screening}

A first series of experiments was performed with $5 \times 10^{5}$ haemocytes /well stimulated with $10 \mu \mathrm{g} / \mathrm{ml}$ PMA and $50 \mu \mathrm{l}$ mixture haemolymph-anticoagulant culture

(a)

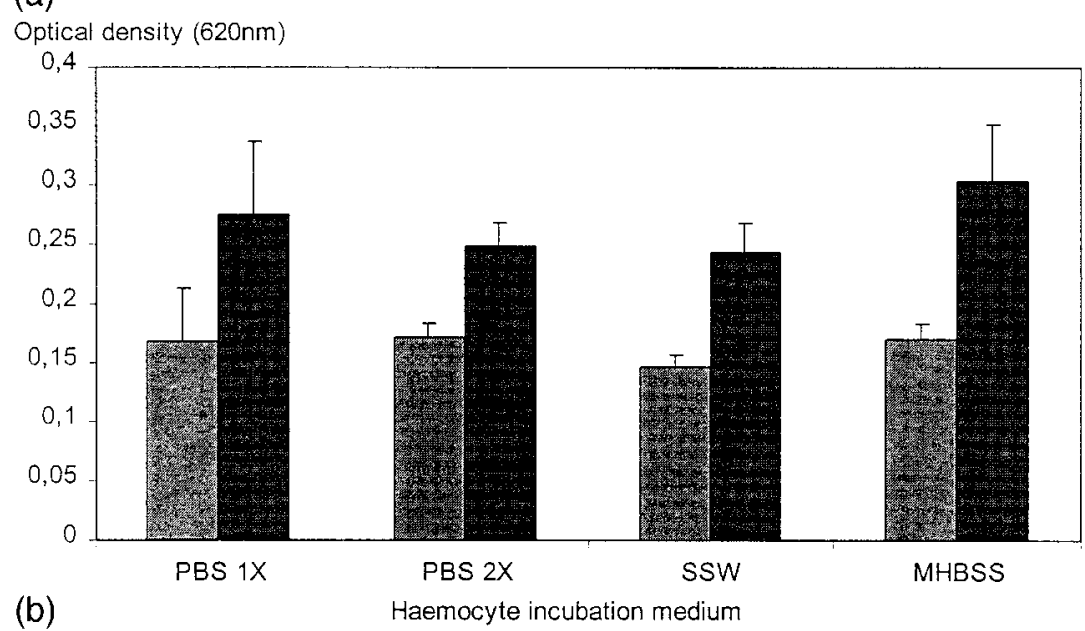

(b)

Haemocyte incubation medium

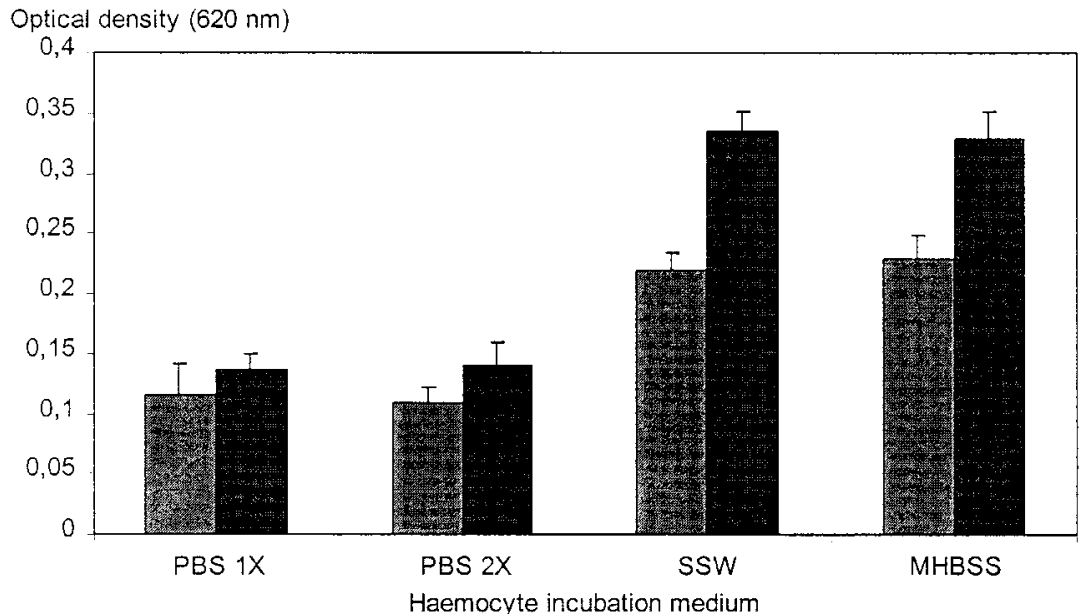

Fig. 1. NBT reduction in haemocytes of P. vannamei in response to different culture media. (a) With the plasma present in all steps of the assay. (b) Without plasma during NBT reduction. $\square$ : In the absence of stimulant. —: In the presence of stimulant $(10 \mu \mathrm{g} / \mathrm{ml}$ PMA). BS: Dulbecco's phosphate-buffered salt solution; SSW: sterile seawater; MHBSS: modified Hank's buffered salt solution. 
medium (PBS $1 \times$, PBS $2 \times$, SSW and MHBSS) remaining during all the steps of the assays (Fig. 1a). MHBSS without divalent cations yielded the best responses in terms of relative production of $\mathrm{O}_{2}^{-}$, corresponding to the $\mathrm{OD}$ ratio of 1.788 between PMA stimulated values and haemocyte base activity values $(0.304 \pm 0.048$ and $0.170 \pm 0.014$, respectively). SSW produced the second best NBT reduction response with a ratio of $1.653(0.243 \pm 0.016$ stimulated and $0.147 \pm 0.010$ base activities $)$. Despite a relatively high base activity, a statistically significant ratio of $1.450(0.248 \pm 0.021$ stimulated and $0.171 \pm 0.012$ base activities) was obtained when haemocytes were incubated in PBS $2 \times$. When haemocytes were incubated in PBS $1 \times$, the ratio of $1.627(0.275 \pm$ $0.061 / 0.169 \pm 0.044)$ was not statistically significant $(p=0.05)$.

When plasma was removed and replaced by medium before incubation with the stimulus, SSW and MHBSS again produced the best results with ratios of 1.522 and 1.436, respectively. The haemocytes incubated in PBS $1 \times$ and $2 \times$ did not show any significant reaction to PMA (Fig. 1b).

To standardize the experimental conditions of the assay, it appeared necessary to use synthetic medium instead of SSW, of which the composition can be subject to seasonal and/or environmental variations. Therefore, the effect of MHBSS with different concentrations of $\mathrm{Ca}^{2+}$ and $\mathrm{Mg}^{2+}$ was tested: MHBSS without $\mathrm{Ca}^{2+}$ and $\mathrm{Mg}^{2+}$ (MHBSS), MHBSS with $3 \mathrm{mM} \mathrm{Ca}^{2+}$ and $6.5 \mathrm{mM} \mathrm{Mg}^{2+}$ final concentration (MHBSS-1), with 6 $\mathrm{mM} \mathrm{Ca}^{2+}$ and $13 \mathrm{mM} \mathrm{Mg}^{2+}$ (MHBSS-2), with $9 \mathrm{mM} \mathrm{Ca}^{2+}$ and $19.5 \mathrm{mM} \mathrm{Mg}^{2+}$ (MHBSS-3). The haemocytes incubated in MHBSS-2 presented the best responses with a PMA-stimulated activity of $0.178 \pm 0.026$ OD versus a base activity of $0.089 \pm 0.003$ OD, giving a ratio of 2.0. MBSS-1 and MBSS-3 led to haemocyte responses of 1.526 and 1.314, respectively (Fig. 2). The haemocytes incubated in MHBSS without $\mathrm{Ca}^{2+}$ and $\mathrm{Mg}^{2+}$ showed the responses of 1.39 .

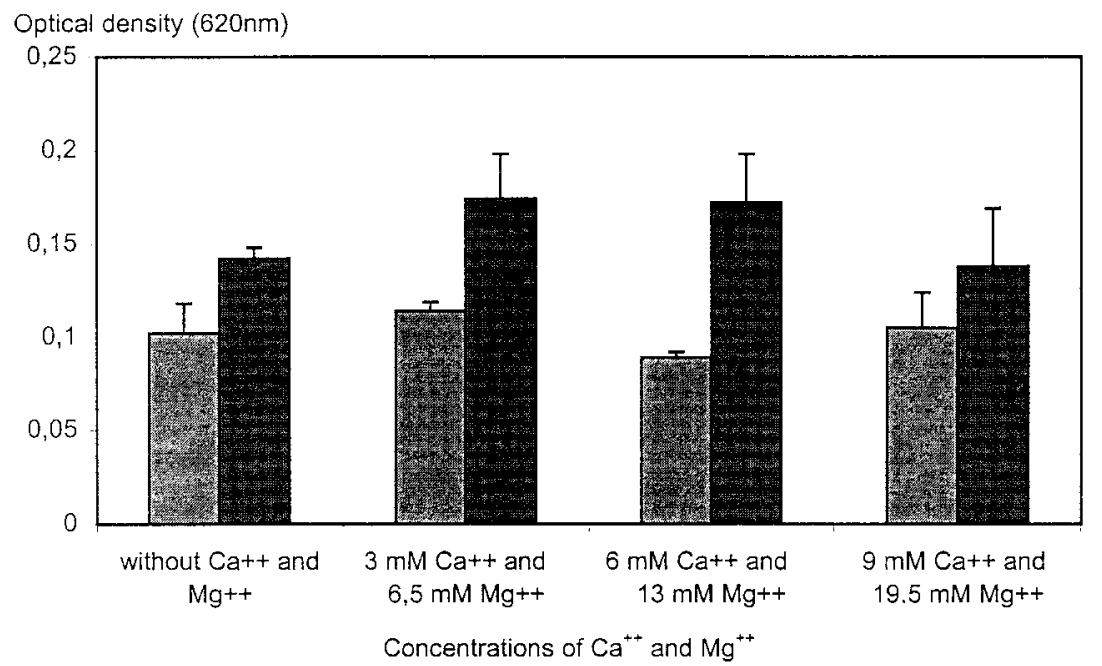

Fig. 2. NBT reduction of the haemocytes kept in MHBSS supplemented with different concentrations of $\mathrm{Ca}^{2+}$ and $\mathrm{Mg}^{2+}$. In the absence of stimulant. $\mathbf{0}$ : In the presence of stimulant $(10 \mu \mathrm{g} / \mathrm{ml}$ PMA). 


\subsubsection{Elicitor nature and concentration}

Equal concentrations of haemocytes $\left(1 \times 10^{5}\right)$ activated with different concentrations of stimulant produced a concentration-dependent increase in the NBT reduction up to final concentrations of $10 \mathrm{mg} / \mathrm{ml}$ laminarin, $40 \mu \mathrm{g} / \mathrm{ml}$ LPS and to $20 / 1$ zymosan/haemocyte ratio, reaching, respectively, OD of $0.092 \pm 0.002,0.103 \pm 0.002$ and $0.105 \pm 0.010$. Haemocytes activated with PMA reached the maximum concentration-dependent activity at $5 \mu \mathrm{g} / \mathrm{ml}$ PMA $(0.099 \pm 0.011)$, the final concentration of 10 $\mu \mathrm{g} / \mathrm{ml}$ inducing an identical level of activity $(0.099 \pm 0.011)$.

No significant differences in NBT reduction were observed between the highest values of the haemocytes activated with the different elicitors assayed ( $p=0.05)$ (Fig. 3).

\subsubsection{Haemocyte concentration}

Different haemocyte concentrations were activated with optimal concentrations of PMA, zymosan and laminarin. The amount of formazan increased significantly with the number of haemocytes, with no significant differences $(p=0.05)$ between the elicitors used at the same number of haemocytes (Fig. 4).

\subsubsection{Specific inhibition}

3.1.4.1. Effect of SOD. The addition of SOD to haemocytes stimulated with $10 \mu \mathrm{g} / \mathrm{ml}$ PMA appeared to produce a inhibition of the NBT reduction. However, only at the SOD concentration of $300 \mathrm{U} / \mathrm{ml}$, was the effect statistically significant (Fig. 5).

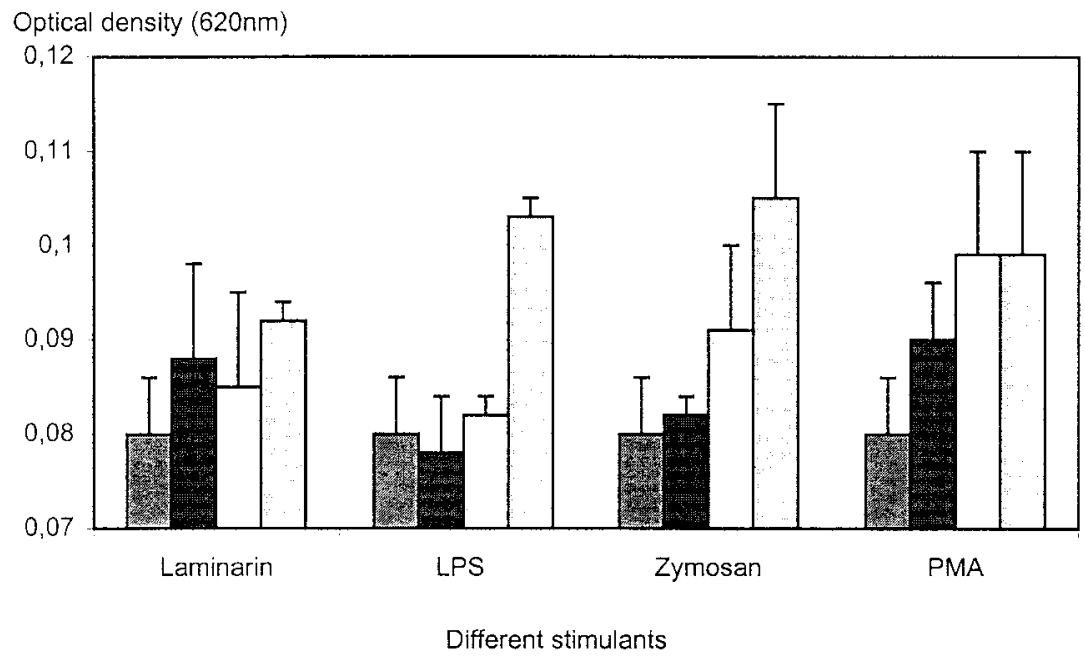

Fig. 3. Effect of different stimulants of the respiratory burst on haemocytes of $P$. vannamei, using three concentrations of stimulant described below. Darkly shaded bar: Without stimulant. Filled bar: $1 \mathrm{mg} / \mathrm{ml}$ laminarin, $4 \mu \mathrm{g} / \mathrm{ml}$ of LPS or 5 particles of zymosan/haemocyte, $1 \mu \mathrm{g} / \mathrm{ml}$ of PMA. Unshaded bar: 5 $\mathrm{mg} / \mathrm{ml}$ laminarin, $20 \mu \mathrm{g} / \mathrm{ml}$ of LPS or 10 particles of zymosan/haemocyte, $5 \mu \mathrm{g} / \mathrm{ml}$ of PMA. Lightly shaded bar: $10 \mathrm{mg} / \mathrm{ml}$ laminarin, $40 \mu \mathrm{g} / \mathrm{ml}$ of LPS or 20 particles of zymosan/haemocyte, $10 \mu \mathrm{g} / \mathrm{ml} \mathrm{of}$ PMA. 


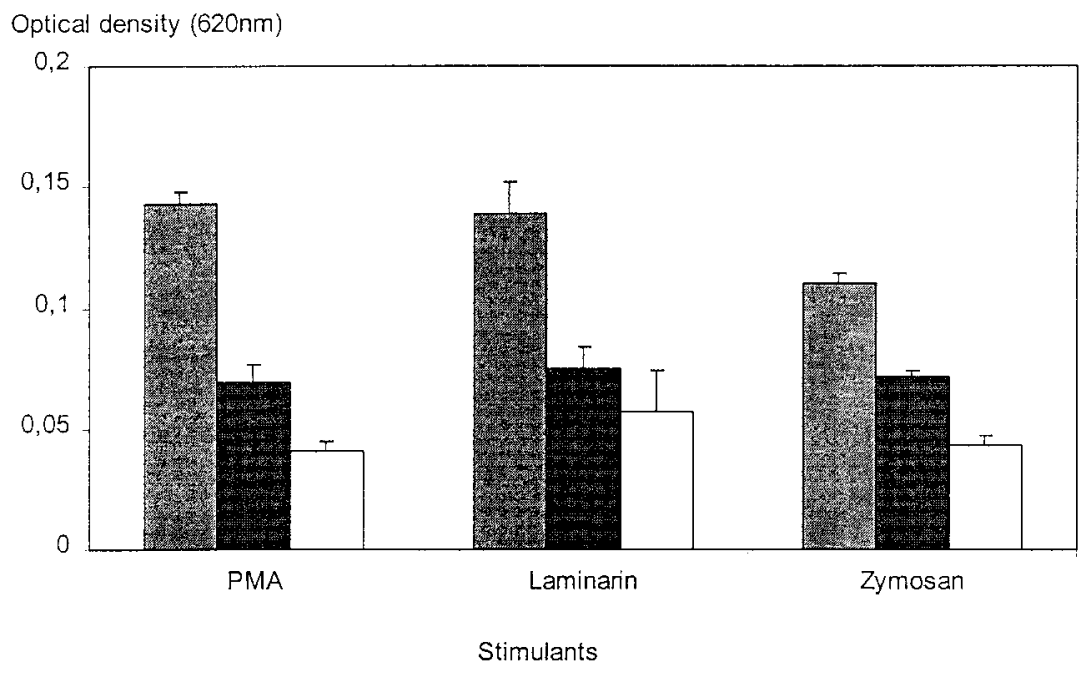

Fig. 4. Response to stimulation of the respiratory burst using different quantities of haemocytes. NBT reduction with $\square: 1 \times 10^{6}, \mathbf{\square}: 5 \times 10^{5}, \square: 1 \times 10^{5}$ haemocytes. The haemocytes were stimulated with 10 $\mu \mathrm{g} / \mathrm{ml}$ of PMA, $10 \mathrm{mg} / \mathrm{ml}$ of laminarin or 20 particles of zymosan/haemocyte.

3.1.4.2. Effect of NEM and iodoacetamide. Adding of $1 \mathrm{mM}$ and higher of NEM or 1 $\mathrm{mM}$ and higher of iodoacetamide, completely inhibited the haemocyte activity of NBT reduction (Fig. 5).

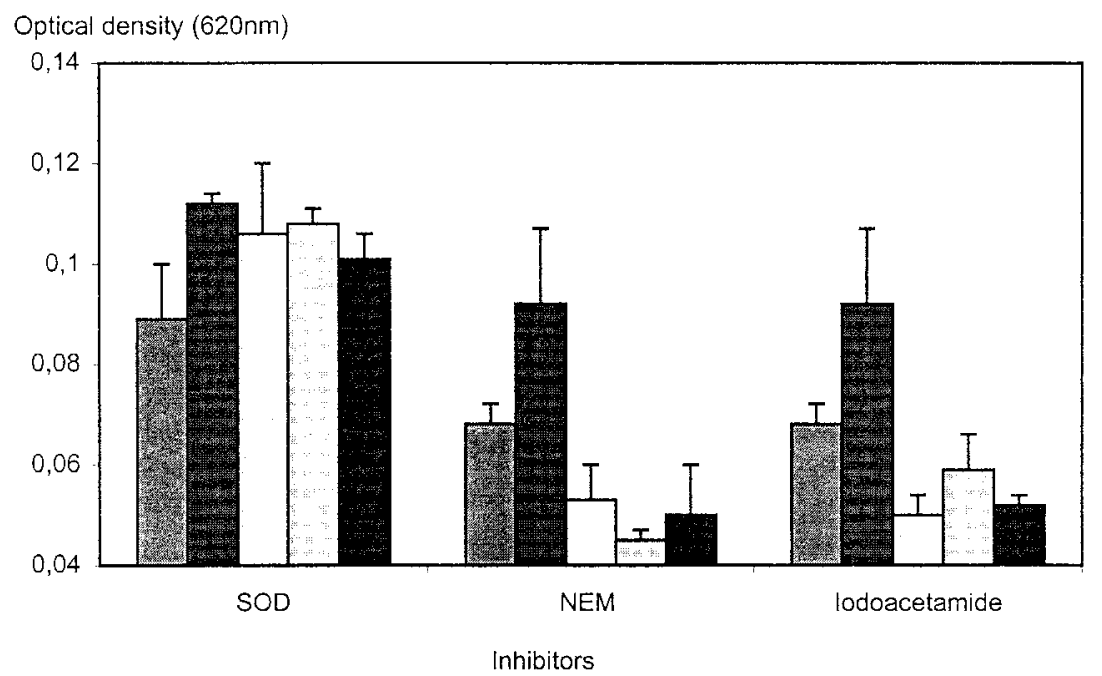

Fig. 5. Effect of different inhibitors of the respiratory burst on NBT reduction using haemocytes previously stimulated with $10 \mu \mathrm{g} / \mathrm{ml}$ of PMA. Darkly shaded bar: Without stimulant and inhibitor. Filled bar: Stimulated. Unshaded bar: Stimulated and inhibited with $75 \mathrm{U} / \mu \mathrm{l}$ of SOD, $1 \mathrm{mM}$ of NEM, $1 \mathrm{mM}$ of iodoacetamide. Lightly shaded bar: Stimulated and inhibited with $150 \mathrm{U} / \mu 1$ of SOD, $3 \mathrm{mM}$ of NEM, $10 \mathrm{mM}$ of iodoacetamide. Filled bar: Stimulated, and inhibited with $300 \mathrm{U} / \mu 1$ of SOD, $5 \mathrm{mM}$ of NEM, $20 \mathrm{mM}$ of iodoacetamide. 


\subsubsection{Application of optimized NBT reduction assay}

3.1.5.1. Individual variability in shrimp haemocyte superoxide anion production. Quantitative analysis of the production of $\mathrm{O}_{2}^{-}$was performed with individual shrimps. The NBT reduction responses obtained with equal numbers of haemocytes revealed a high degree of individual variability, 2 out of 10 animals not showing any response at all to stimulation by PMA. A variability was also identified in the number of haemocytes per milliliter of haemolymph $\left(29.17 \pm 7.56 \times 10^{6}\right)$ (Fig. 6).

3.1.5.2. Bacterial phagocytosis and effect on haemocyte superoxide anion production. Different bacterial strains were assayed for their capacity to induce haemocyte production of $\mathrm{O}_{2}^{-}$. Different bacteria to haemocyte ratios were tested, 10/1, 20/1 and 40/1. Live bacteria of all strains assayed, except $V$. harveyi, were able to induce the production of superoxide anion in the haemocytes with the higher activities recorded for the ratio 40 bacteria to one haemocyte. However, the reduction resulting for all the bacteria at 10/1 and 20/1 were not significantly different $(p=0.05)$ from the control (Fig. 7a). No activity was recorded with heat-killed M. luteus, E. coli D31 and V. harveyi at any of the bacteria/haemocyte ratios used. Significant activity $(p=0.05)$ of the haemocytes was detected with heat-killed $V$. alginolyticus only at the ratio 40/1. Heat-killed $V$. anguillarum lead to haemocyte production of superoxide anion in a dose dependent manner (Fig. 7b), but only at the ratio 40/1 was the difference statistically significant.

Microscopic observation showed that bacteria had been engulfed by the haemocytes. This holds true for both live and heat-killed bacteria. Although $V$. harveyi did not elicit a response in the haemocytes, it had been phagocytosed.

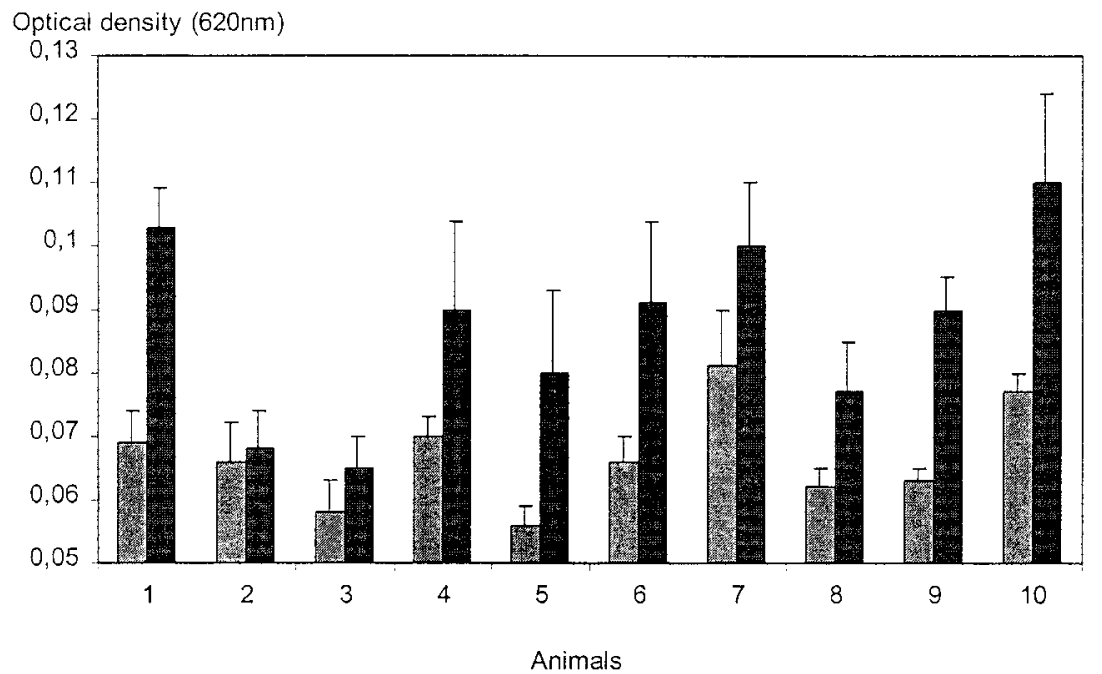

Fig. 6. Variations of NBT reduction amongst 10 different shrimps $\left(5 \times 10^{5}\right.$ haemocytes $)$. $\square$ : Without stimulant. $\mathbf{m}$ : In the presence of $10 \mu \mathrm{g} / \mathrm{ml}$ of PMA. 

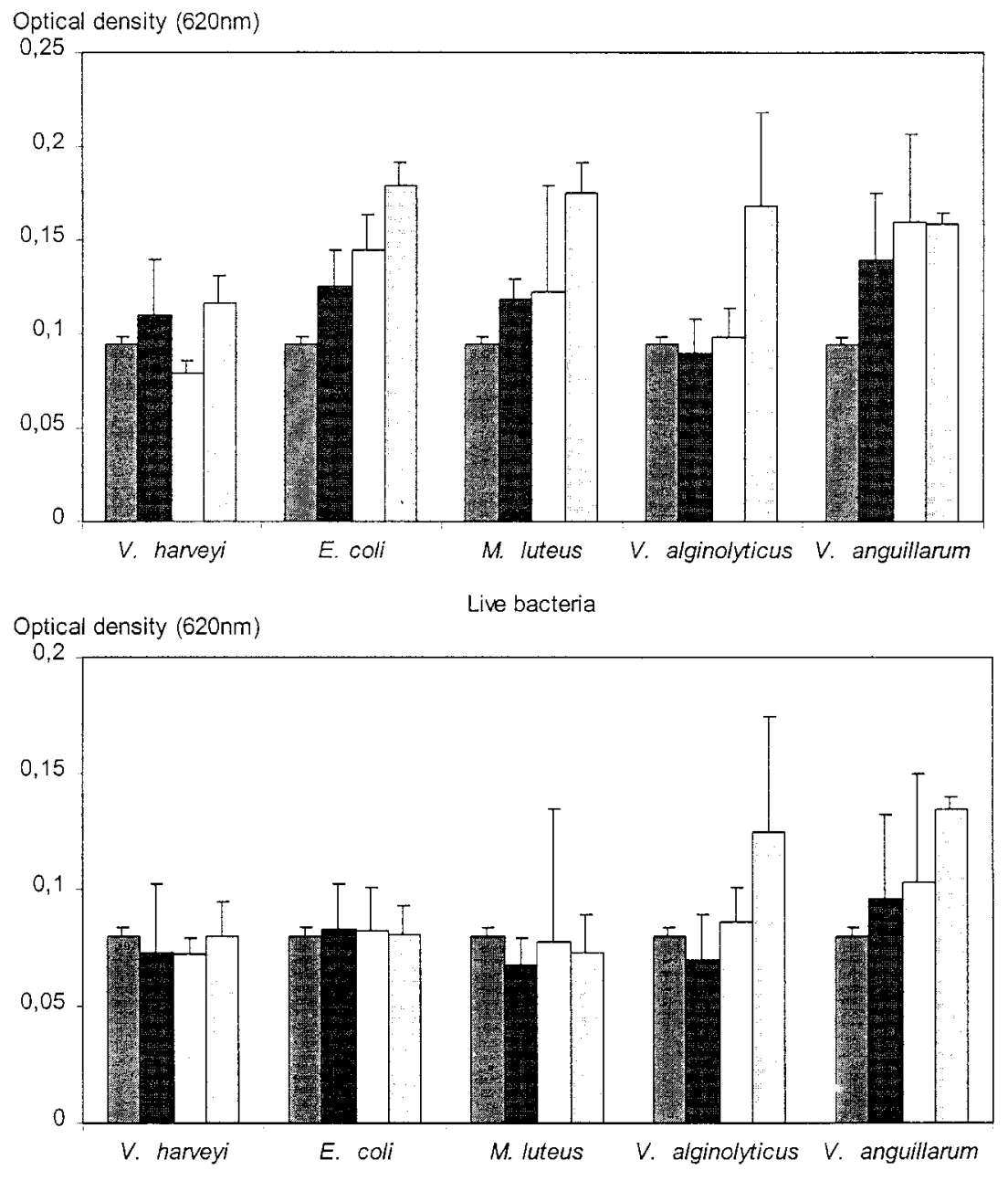

Heat killed bacteria

Fig. 7. NBT reduction in $5 \times 10^{5}$ haemocytes of $P$. vannamei, in response to stimulation with different bacterial strains, using live bacteria (a) and heat-killed bacteria (b). Three different concentrations of bacteria were used, as indicated below. Darkly shaded bar: Without stimulant. Filled bar: 10 bacteria/haemocyte for each strain. Unshaded bar: 20 bacteria/haemocyte for each strain. Lightly shaded bar: 40 bacteria/haemocyte for each strain.

3.1.6. Effect of the environmental stressor propiconazole (Tilt $\left.{ }^{\circledR}\right)$ on superoxide anion production

We performed NBT reduction assays in the presence of the antifungal agent propiconazole at final concentrations of 1,10 and $100 \mathrm{ppb}$ (in vitro exposure). Fig. 8 shows a significant increase of the base activity in unstimulated cells, with increasing propiconazole concentrations. However, when the haemocytes were stimulated with PMA, we observed a significant decrease of $\mathrm{O}_{2}^{-}$generation at $1 \mathrm{ppb}$ of propiconazole. 


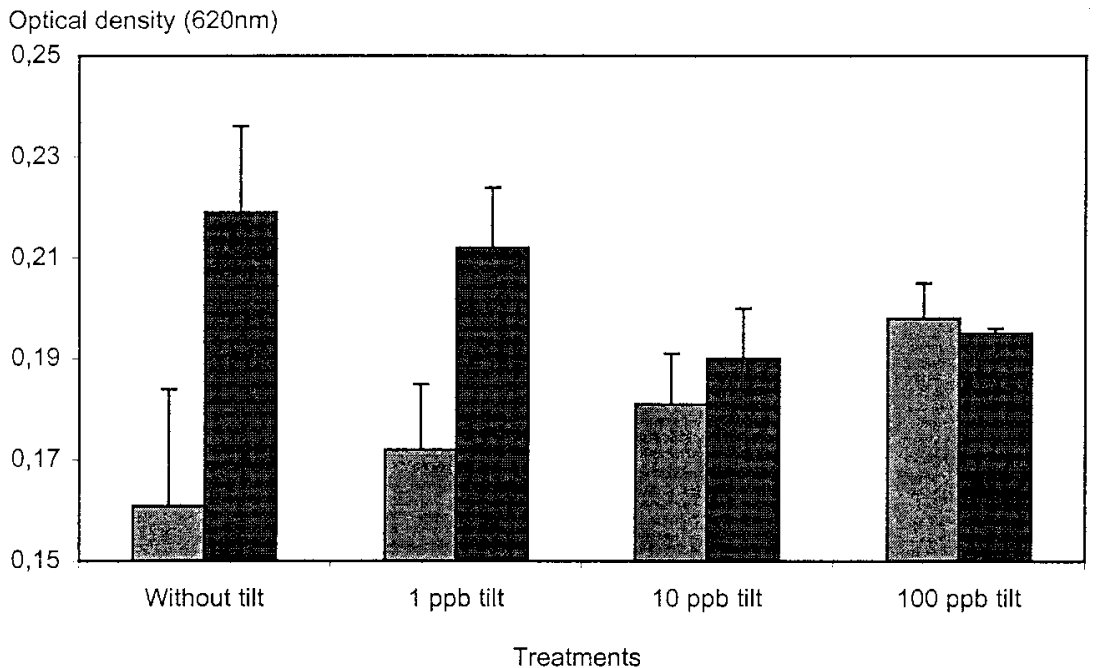

Fig. 8. NBT reduction by $1 \times 10^{6}$ haemocytes in direct contact with the fungicide Tilt ${ }^{\circledR}$. $\square$ : In the absence of stimulant. $\mathbf{~ : ~ I n ~ t h e ~ p r e s e n c e ~ o f ~} 10 \mu \mathrm{g} / \mathrm{ml}$ of PMA.

The cellular response to stimulant drops completely to the level of unstimulated cells at 10 and $100 \mathrm{ppb}$ of propiconazole.

\section{Discussion}

The NBT reduction assay is widely used to detect the production of superoxide anions within phagocytic cells. The measurement of $\mathrm{O}_{2}^{-}$is considered to be an accurate method for estimating the cell's capability to generate a respiratory burst. Compared to other methods such as CL, this assay can be assumed less sensitive because detecting only intracellular $\mathrm{O}_{2}^{-}$activity. The method of CL permits to measure, both intracellularly and extracellularly, the whole of the different ROIs generated upon stimulation of the cell. Luminol-enhanced CL is thought to detect primarily the cellular myeloperoxidase-hydrogen peroxide-halide system (DeChatelet et al., 1982), whereas lucigeninenhanced CL would rather measure the production of the superoxide anion (Gyllenhammar, 1987). Measurements must be conducted with an automatic luminometer or with a scintillation counter, and this provides quantitative analyses and kinetics of the respiratory burst activities. However, the NBT reduction assay presents some advantages. The method can be performed in microplates, allowing the study of 96 samples at a time, and providing both qualitative and quantitative analyses. Moreover, the process of phagocytosis and the intracellular $\mathrm{O}_{2}^{-}$production can be followed by microscopic examination. Also, the quantification of superoxide anion production is rendered possible by spectrophotometric analyses of solubilized formazan deposits (Secombes, 1990). The method is fast, simple, and relatively cheap because a luminometer or scintillation counter is not needed. On top of that, cells do not have to be separated from plasma; 
handling steps, which can have deleterious effect on haemocyte functionality, are consequently reduced. This represents a great advantage for shrimp haemocytes, which are very labile and difficult to manipulate in vitro.

This study shows in vitro production of the superoxide anion by $P$. vannamei haemocytes, submitted to respiratory burst stimulants. The specificity of the response has been verified by inhibition experiments with SOD, which catalyses the dismutation of $\mathrm{O}_{2}^{-}$into hydrogen peroxide. The involvement of $\mathrm{O}_{2}^{-}$has also been verified by using NEM which is known as an inhibitor of some cytosolic cofactors involved in the activation of the enzyme generating $\mathrm{O}_{2}^{-}$, NADPH oxidase, as well as iodoacetamide, an inhibitor of the respiratory burst (Pick et al., 1981). The first aim of the work was to optimize the parameters of the assay (NBT reduction) in order to increase sensitivity when working with low numbers of haemocytes. This is particularly important for further applications of the method in analyses of respiratory burst activities of individual shrimps, and of juvenile shrimps with limited haemolymph volumes and haemocyte numbers.

For optimizing the NBT assay, we paid attention to the choice of culture medium in which the haemocytes were held before and during the production of intracellular $\mathrm{O}_{2}^{-}$. We have also considered the differences between the NBT reduction values of unstimulated haemocytes and those obtained following stimulation. The haemocyte base activities correspond to spontaneous $\mathrm{O}_{2}^{-}$production, which may reveal a normal physiological cell activity. To a certain degree, $\mathrm{O}_{2}^{-}$production can be related to an activation of the haemocytes during the isolation procedure, or when the haemocytes adhere to the plastic as observed for instance for bivalve haemocytes (Pipe, 1992). Avoiding activation of the haemocytes during handling steps is essential until when incubating them in suitable medium for specific respiratory burst stimulation. For that, it is advisable to use an anticoagulant solution that maintains the haemocytes in a quiescent, non-stimulable state. A spontaneous activation can also result from the effect of the medium used for incubating the haemocytes, as shown in vertebrate blood cells (Bowman et al., 1985) and, in our study, when incubating haemocytes in Dulbecco's PBS. High base activity values may reveal stressful or injurious situations due to in vitro factors. However, in another respect, high base activity can also reflect a physiological state of the shrimp, representing inflammatory or stressful reactions. In any case, subsequent stimulation with a specific trigger of the respiratory burst could be impaired, ineffective or unreliable. We have shown that the reaction media substantially influenced the production of $\mathrm{O}_{2}^{-}$and subsequent NBT reduction. It is well established that calcium $\left(\mathrm{Ca}^{2+}\right)$ and magnesium $\left(\mathrm{Mg}^{2+}\right)$ are required to initiate phagocytosis and respiratory burst in vertebrate blood cells (Roschger et al., 1990) and marine bivalve haemocytes (Fisher and Newell, 1986; Bachère et al., 1991b). Seawater has been widely used for in vitro assays when marine invertebrate haemocytes functionality is studied because it may provide the haemocytes with cations or other essential elements for their successful stimulation and activity. However, natural seawater not having a constant composition, for development of standardized assays the use of synthetic medium of determined composition is more advisable. Comparison of $\mathrm{O}_{2}^{-}$production obtained using sterile seawater and MHBSS, complemented with suitable concentrations of $\mathrm{Ca}^{2+}(6 \mathrm{mM})$ and $\mathrm{Mg}^{2+}(13 \mathrm{mM})$, showed that the latter satisfies the functional needs of the haemocytes. 
P. vannamei haemocytes can be stimulated by PMA, zymosan, LPS and laminarin, which lead to similar productions of $\mathrm{O}_{2}^{-}$. In contrast, in adult P. monodon, Song and Hsieh (1994) obtained differences in the stimulative effects of various elicitors. In their experiments, $\beta$-glucan had the stronger effect followed by zymosan and PMA, leading, respectively, to $2.5,2$ and 1.3 times greater activity than unstimulated control cells. Apart from possible interspecies differences, the differences observed in levels of activity between $P$. monodon and, in our experiments, $P$. vannamei, could be partly related to a difference of age. The $P$. monodon specimens used by Song and Hsieh (1994) were adults weighing 30 to $40 \mathrm{~g}$, whereas the $P$. vannamei used in the present study were juvenile animals of about 10 to $13 \mathrm{~g}$. It can be assumed that the haemocyte defence capabilities would be related to age-dependent maturation processes. Little is known about the ontogeny of the immune system in shrimp, and this would merit further attention. The establishment of the defence system could be studied, taking into account possible changes in susceptibility to various pathogens, in relation to the shrimp's age.

A relatively high degree of variability in the production of $\mathrm{O}_{2}^{-}$has been observed between individual animals. A number of factors may influence the NBT reduction activity of individual shrimps, such as their physiological or immune state. Indeed, the generation of $\mathrm{O}_{2}^{-}$has been considered as adapted for the evaluation of the effect of chemical or biological compounds which can modulate the phagocytic capabilities of mammalian cells (Fromtling and Abruzzo, 1985) or marine bivalve haemocytes (Larson et al., 1989; Bachère et al., 1991b; Morvan et al., 1994). The quantification of NBT reduction and the ability of haemocytes to produce ROIs can be considered as functional tests for the evaluation of immune potential at a cellular and organismal level. Further studies will be necessary to analyze the individual variabilities in relation to physiological or infectious parameters, as well as environmental stressful conditions, taking also into account the haemograms. Individual variabilities in NBT reduction may be related to differential compositions of haemocyte subpopulations. Indeed, using the method of ferricytochrome- $C$ reduction, separated hyaline cells of $C$. maenas were shown to generate $\mathrm{O}_{2}^{-}$, whereas the stimulation of semi-granular and granular populations did not result in a significant reduction of ferricytochrome- $C$ (Bell and Smith, 1993). The establishment of methods for separating shrimp haemocytes (Rodriguez et al., 1995) will allow to analyze the microbicidal oxidative function of the different cell subpopulations in shrimp.

The possible involvement of shrimp haemocyte ROIs in the elimination of bacteria was investigated. We used the Gram-positive bacterium M. luteus, and several Gramnegative bacteria $E$. coli $\mathrm{D} 31$ and Vibrio strains, as $V$. harveyi, pathogen for $P$. vannamei (Robertson et al., 1998), V. alginolyticus, named Ili (I. Morales, personal communication), observed in the shrimp microflora, and $V$. anguillarum considered potentially harmful for shrimps (Lightner, 1983). Under the experimental conditions all the strains except $V$. harveyi, added to the haemocytes as phagocytosis elicitors, when used alive were able to induce the generation of $\mathrm{O}_{2}^{-}$. The response of the haemocytes was dependent on the concentration of bacteria, especially as shown with E. coli. However, in a general way, this capacity disappeared when the bacteria were previously heat-killed. Only the killed $V$. alginolyticus and $V$. anguillarum, at the bacteria-tohaemocyte ratio of $40 / 1$, were able to induce a significant activity in the haemocytes. 
The loss of inductive potential of the heat-killed bacteria is probably caused by heat-induced modifications of some membrane components, involved in their recognition by the haemocytes.

If considering studies of the interactions between shrimp and possible pathogens and probiotics, the NBT reduction assay appears to be an interesting tool. The fact that the $V$. harveyi strain, alive and heat-killed, cannot stimulate the production of $\mathrm{O}_{2}^{-}$in a pool of haemolymph of $P$. vannamei, can be explained by its ability to avoid this immune barrier. This may represent part of this strain's pathogenicity. In contrast, both heat-killed and live $V$. alginolyticus, Ili strain, with probiotic effects in larvae of $P$. vannamei, are able to stimulate haemocyte $\mathrm{O}_{2}^{-}$production using the same pool of haemolymph. On the other hand, it is interesting to note that in another experiment, using haemolymph from different individual shrimps ( $P$. vannamei) and the same strain of $V$. harveyi (data not shown), there were a few shrimps with a rather high ratio of stimulation for production of $\mathrm{O}_{2}^{-}$. These results may imply the utility of this tool for the selection strategy.

To know the immune and physiological conditions of shrimps is important information for the management of shrimp aquaculture. For measuring these conditions, the shrimp farmers used different criteria (salinity stresses, activity of the shrimps, origin of the shrimps, etc.) with relative success at the production level. In this context, the immune check-up may represent a welcome and effective criterion that may help increase success in shrimp production. For measuring of the shrimp's immunological activity state and potential, simple quantitative assays such as the NBT reduction assay or other tools can be developed. This information can provide the shrimp producers the criteria of susceptibility or deficiencies at resistance level of the animals, and represent an alternative in health management of the shrimp aquaculture.

In order to see if the fungicide propiconazole (Tilt ${ }^{\circledR}$ ) has an action upon $\mathrm{O}_{2}^{-}$ generation, we performed a NBT reduction assay in the presence of this compound. The data obtained from unstimulated haemocytes in this in vitro assay suggest that propiconazole enhances the release of ROIs, by a sort of inflammatory reaction (effect on base activity). These findings might be explained by biochemical events of detoxification because, during phase I of the biotransformation of lipophilic chemicals by the P-450 monooxigenase system, reactive oxygen species as well as free radicals derived from the xenobiotics can be generated (Bainy et al., 1996). It is well known that free radicals including reactive oxygen species may react with several biomolecules, viz. nucleic acids, lipids, carbohydrates and proteins, and in doing so damage the cells. These perturbations are believed to underlie tissue injuries (De Groot, 1994) and physiological disorders (Kim, 1997. Another effect of this Tilt ${ }^{\circledR}$-caused generation of oxygen radicals, is the drain of the cellular pool of reducing agents (NAD, NADPH, GSH). This impairs the metabolic processes (Di Giulio et al., 1995), including the important antimicrobial mechanism, the respiratory burst. This fact is in accordance with the dose-related decrease in $\mathrm{O}_{2}^{-}$generation by PMA-stimulated haemocytes exposed to the fungicide. If propiconazole exert the same effects in vivo as we measured in vitro, this could have the consequence that antimicrobial defences would be impaired. Experiments testing the effect of in vivo administration of propiconazole are presently being conducted. On the other hand, in vivo-administered immunostimulants and vaccines (e.g., Sung et al., 1994; Teunissen et al., 1998) probably enhance antimicrobial 
defences, as they confer protection against bacterial infections. This may be due to their stimulating the ROI producing mechanism. Clearly, studies need to be done into the in vivo effects of immunostimulatory and of immunoinhibitory substances on both the respiratory burst and antimicrobial defences in aquacultured crustacea. Such studies have not yet been done. In fishes however, it was shown that increased $\mathrm{O}_{2}^{-}$production, induced in vivo with polysaccharides, is related with the increment of survival rate after bacterial infections (Wang and Wang, 1997).

Moreover, propiconazole is one of the ergosterol biosynthesis inhibiting fungicides (EBIFs). In fungi, these compounds act on sterol 14- $a$-dimethylase, a microsomal cytochrome $P 450$-dependent enzyme system. In vertebrates, the EBIFs have complex patterns of induction, suppression and inhibition of cytochrome $P 450$ isozymes according to both the fungicide and the species (Van den Bossche et al., 1995). In crustaceans, there are no data in this respect, but taking into account the geographic situation of an important number of shrimp farms, it may be of interest to study the potentially toxic interaction between propiconazole (and other environmental stressors like other pesticides, and antibiotics used in aquaculture) present in the shrimp-farming environments.

In conclusion, the present study shows that the spectrophotometric measurement of NBT reduction is a reliable method to demonstrate in a quantitative way the production of superoxide by haemocytes of $P$. vannamei. Standardized conditions (number of haemocytes, incubation medium, type and concentration of stimulus) were determined. With the optimized assay, it could be demonstrated that there is an important variability in the activity among individual shrimps, that live bacteria - with the exception of the pathogenic $V$. harveyi - do induce the production of superoxide, and that the fungicide Tilt ${ }^{\circledR}$ enhances the background activity of haemocytes but reduces PMA-induced activity. We believe that this method may prove a useful tool to measure the health condition and immunological status of individual shrimps.

\section{Acknowledgements}

The authors express their appreciation to Ac. Ernesto Valenzuela and Ac. Jean Jacques Thibaut for their assistance and collaboration.

\section{References}

Adema, C., van der Knaap, M., Sminia, W.P.W., 1991. Molluscan haemocyte mediated cytotoxicity: the role of reactive oxygen intermediates. Rev. Aquat. Sci. 4, 201-223.

Ahmad, S., 1995. Oxidative stress from environmental pollutants. Arch. Insect Biochem. Physiol. 2, $135-157$.

Akard, L.P., English, D., Gabig, T.C., 1988. Rapid deactivation of NADPH-oxidase in neutrophils: continuous replacement by newly activated enzyme sustains the respiratory burst. Blood 72, 322-327.

Auclair, C., Voisin, E., 1985. Nitroblue tetrazolium reduction. In: Greewald, R.A (Ed.), CRC Handbook of Methods for Oxygen Radical Research. CRC Press, Boca Raton, FL, pp. 123-132.

Babior, B.M., 1984. Oxidants from phagocytes: agents of defense and destruction. Blood 64, 959-966.

Bachère, E., Mialhe, E., Rodriguez, J., 1995. Identification of defence effectors in the haemolymph of crustaceans with particular reference to the shrimp Penaeus japonicus (Bate): prospects and applications. Fish Shellfish Immunol. 5, 597-612. 
Bachère, E., Noël, T., Mialhe, E., 1991a. Effects of environmental pollutants and chemotherapeutic agents on the chemiluminescence of the hemocytes from the oyster Crassostrea gigas. Eur. Aquacult. Soc., Spec. Publ., Dublin, 14-15.

Bachère, E., Hervio, D., Mialhe, E., 1991b. Luminol-dependent chemiluminescence by hemocytes of two marine bivalves, Ostrea edulis and Crassostrea gigas. Dis. Aquat. Org. 11, 173-180.

Bainy, A., Saito, E., Paulo, S.M., Carvalho, V., Junqueira, V.B., 1996. Oxidative stress in gill, erytrhrocytes, liver and kidney of Nile tilapia (Oreochomis niloticus) from polluted site. Aquat. Toxicol. 34, 151-162.

Bayne, C.J., 1990. Phagocytosis and non-self recognition in invertebrates. Phagocytosis appears to be an ancient line of defence. Bioscience 40, 723-731.

Bell, K.L., Smith, V.J., 1993. In vitro superoxide production by hyaline cells of the shore crab Carcinus maenas (L.). Dev. Comp. Immunol. 17, 211-219.

Bowman, C.M., Berger, E.M., Butler, E.N., Toth, K.M., Repine, J.E., 1985. HEPES may stimulate cultured endothelial cells to make growth-retarding oxygen metabolites. In Vitro Cell. Dev. Biol: Anim. 21 (3), $140-142$.

De Groot, H., 1994. Reactive oxygen species in tissue injury. Hepatogastroenterology 4, 328-332.

DeChatelet, L.R., Long, G.D., Shirley, P.S., Bass, D.A., Thomas, M.J., Henderson, F.W., Cohen, M.S., 1982. Mechanism of the luminol-dependent chemiluminescence of human neutrophils. J. Immunol. 129, 15891593.

Di Giulio, R.T., Benson, W.H., Van Veld, P.A., 1995. Biochemical mechanism: metabolism, adaptation, and toxicity. In: Rand, G.M. (Ed.), Fundamentals Aquatic Toxicology. 2nd edn. Taylor \& Francis, Washington, DC, pp. 523-561.

Dikkeboom, R., van der Knaap, W.P.W., Meuleman, E.A., 1987. Hemocytes of the pond snail Lymnaea stagnalis generate reactive forms of oxygen. J. Invertebr. Pathol. 49, 321-331.

Fisher, W., Newell, R., 1986. Salinity effects on the activity of granular hemocytes of American oysters, Crassostrea virginica. Biol. Bull. 170, 122-134.

Fromtling, R.A., Abruzzo, G.K., 1985. Chemiluminescence as a tool for the evaluation of antimicrobial agents: a review. Methods Find. Exp. Clin. Pharmacol. 7, 493-500.

Gyllenhammar, H., 1987. Lucigenin chemiluminescense in the assessment of neutrophil superoxide production. J. Immunol. Methods 2, 209-213.

Hervio, D., Bachère, E., Mialhe, E., Grizel, H., 1989. Chemiluminescent responses of Ostrea edulis and Crassostrea gigas hemocytes to Bonamia ostrea (Ascetospora). Dev. Comp. Immunol. 13 (4), 449.

Kim, K.B., 1997. Oxidative stress to DNA, protein, and antioxidant enzymes (superoxide dismutase and catalase) in rats treated with benzo[ $a$ ]pyrene. Cancer Lett. 1-2, 205-212.

Larson, K.G., Roberson, B.S., Hetrick, F.M., 1989. Effect of environmental pollutants on the chemiluminescence of hemocytes from the American oyster Crassostrea virginica. Dis. Aquat. Org. 6, 131-136.

Le Gall, G., Bachère, E., Mialhe, E., 1991. Chemiluminescence analysis of the activity of Pecten maximus hemocytes stimulated with zymosan and host-specific Rickettsiales-like organisms. Dis. Aquat. Org. 11, $181-186$.

Lightner, D.V., 1983. Diseases of cultured penaeid shrimp. In: McVey, J.P. (Ed.), CRC Handbook of Mariculture vol. 1 CRC Press, Boca Raton, FL, pp. 289-320.

Morvan, A., Bachère, E., Pinto Da Silva, P., Pimenta, P., Mialhe, E., 1994. In vitro activity of the antimicrobial peptide magainin 1 against Bonamia ostreae, the intrahemocytic parasite of the flat oyster Ostrea edulis. Mol. Mar. Biol. Biotechnol. 3, 327-333.

Pick, E., Charon, J., Mizel, D., 1981. A rapid densitometric microassay for nitroblue tetrazolium reduction and application of the microassay to microphages. J. Reticuloendothel. Soc. 30, 581-593.

Pipe, R.K., 1992. Generation of reactive oxygen metabolites by the haemocytes of the mussel Mytilus edulis. Dev. Comp. Immunol. 16, 111-122.

Robertson, P.A.W., Calderon, J., Carrerra, L., Stark, J.R., Zherdmant, M., Austin, B., 1998. Experimental Vibrio harveyi infections in Penaeus vannamei larvae. Dis. Aquat. Org. 32, 151-155.

Rodriguez, J., Boulo, V., Mialhe, E., Bachère, E., 1995. Characterisation of shrimp haemocytes and plasma components by monoclonal antibodies. J. Cell Sci. 108, 1043-1050.

Roschger, P., Graninger, W., Klima, H., 1990. Magnesium-dependent induction of phagocytosis-associated chemiluminescence of adherent human polymorphonuclear leukocytes by non-opsonized zymosan. J. Biolumin. Chemilumin. 5, 31-36. 
Secombes, C.J., 1990. Isolation of salmonid macrophages and analysis of their killing activity. Tech. Fish Immunol. 1, 137-154.

Söderhäll, K., Cerenius, L., 1998. Role of the prophenoloxidase-activating system in invertebrate immunity. Curr. Opin. Immunol. 10, 23-28.

Song, Y.L., Hsieh, Y.T., 1994. Immunostimulation of tiger shrimp (Penaeus monodon) hemocytes for generation of microbicidal substances: analysis of reactive oxygen species. Dev. Comp. Immunol. 18 (3), 201-209.

Sung, H.H., Kuo, G.H., Song, Y.L., 1994. Vibriosis resistance induced by glucan treatment in tiger shrimp (Penaeus monodon). Fish Pathol. 29, 11-17.

Teunissen, O.S.P., Faber, R., Booms, G.H.R., Latscha, T., Boon, J.H., 1998. Influence of vaccination on vibriosis resistance of the giant black tiger shrimp Penaeus monodon (Fabricius). Aquaculture 164, 359-366.

Van den Bossche, H., Koymas, L., Moereels, H., 1995. P 450 inhibitors of use in medical treatment: focus on mechanisms of action. Pharmacol. Ther. 1, 79-100.

Volety, A.K., Chu, F.L.E., 1995. Suppression of chemiluminescence of eastern oyster (Crassostrea virginica) hemocytes by the protozoan parasite Perkinsus marinus. Dev. Comp. Immunol. 19 (2), 135-142.

Wang, W.S., Wang, D.H., 1997. Enhancement of the resistance of tilapia and grass carp to experimental Aeromonas hydrophyla and Edwardsiella tarda infections by several polysaccharides. Comp. Immunol. Microbiol. Infect. Dis. 20 (3), 261-270. 